\title{
Investigation of 40 Gbps DWDM Optical System by using Hybrid Optical Amplifier with Different Modulation Formats
}

\author{
Daleep Singh Sekhon*, Jyotsana and Jyoteesh Malhotra \\ Department of Electronics and Communication Engg., GNDU Regional Campus, \\ Jalandhar-144008, Punjab. India \\ *Corresponding Author E-mail: dssekhon24@gmail.com
}

\begin{abstract}
This paper demonstrates the comparison of 40 Gbps DWDM system using hybrid optical amplifier configurations (EDFA-EDFA and EDFA-SOA) are implemented with $R Z$ and NRZ encoding techniques at various distance along with DCF having dispersion $80 \mathrm{ps} / \mathrm{nm} / \mathrm{Km}$. DWDM systems with 4 channels each having a bit rate of 10 Gbps and 0.8 $n m$ equal channel spacing. The performance of EDFA-EDFA and EDFA-SOA hybrid optical amplifiers with different modulation formats (NRZ and RZ) are evaluated in terms of BER, eye height and Q-factor. EDFA-EDFA performed better upto $200 \mathrm{~km}$ as compared to EDFA-SOA optical amplifiers at $100 \mathrm{~km}$ distance with NRZ format. For RZ format EDFA-EDFA performance of DWDM system is also good upto $250 \mathrm{~km}$ as compared to EDFA-SOA upto $120 \mathrm{~km}$. In this paper, DWDM system using EDFA-EDFA yields better result than EDFA-SOA and also for RZ encoding technique communication is achieved more distance than NRZ encoding technique.
\end{abstract}

Keywords: DWDM, EDFA-EDFA, EDFA-SOA, NRZ, RZ

\section{Introduction}

The development of the Dense wavelength division multiplexing (DWDM) technique has opened new avenues for all-optical devices, which compensate for signal losses while performing data regeneration (i.e., dispersion compensation) with lower cost than its electronic counterpart. Dense Wavelength division multiplexing (DWDM) has become the preferred transmission technology in the transport network of long distance communication. The advances in the optical communications have been promoted in part by development of efficient and powerful optical amplifiers which eliminate the need of costly converter from optical to electrical signal and vice versa. Due to the recent advance in wideband optical amplifiers, the communication is possible in DWDM systems at terabit per second data rates. A particular attraction of EDFAs is their large gain bandwidth, which is typically tens of nanometers and thus actually more than enough to amplify data channels with the highest data rates without introducing any effects of gain narrowing. To cater to the demand for an increasing number of channels, high signal powers are required at the output of each amplifier in the network link. Cascaded/multistage amplifiers can provide such high signal powers, but require extremely severe operating conditions. Hybrid amplifiers have many advantages over individual amplifiers, like wide gain bandwidth and more flat gain profile. Hybrid amplifier provides high power gain. In literature review, compare the performance of DRA-EDFA, DRA-SOA hybrid optical amplifier in DWDM systems and finds DRAEDFA yields a better result on the basis of eye diagram [1]. Comparison of different hybrid optical amplifier(EDFA-RAMAN, RAMAN SOA, EDFA-SOA) on the basis of Qfactor, bit-error rate, output power at different distances and finds EDFA-RAMAN provides a better result than other hybrid amplifier [2]. Investigation of different optical amplifiers for less number of channels with large channel spacing using eye pattern, BER 
and Q factor and get optimized transmission distance to transmit the signal [3]. Implementation of different hybrid amplifier configurations with two and three pumps to obtain a flat global gain for a large bandwidth region [4]. Simulative analysis of 16 channel WDM systems at $10 \mathrm{Gbps}$ for the various optical amplifiers and hybrid optical amplifiers and the performance had been compared on the basis of transmission distance and dispersion. The amplifiers EDFA and SOA had been investigated independently and further compared with hybrid optical amplifiers like RAMAN-EDFA and RAMAN-SOA. It was observed that hybrid optical amplifier RAMAN-EDFA provides good results on the basis of the highest output power and the least bit error rate at $100 \mathrm{~km}$ for dispersion 2 $\mathrm{ps} / \mathrm{nm} / \mathrm{km}$ and $4 \mathrm{ps} / \mathrm{nm} / \mathrm{km}$ respectively [5]. Investigation of 40 Gbps high capacity long haul network with different modulation format for compensating dispersion in the presence of Kerr's effect and comparison had been done with different dispersion compensating techniques on the basis of eye diagram [6].

\section{System Design}

To investigate the performance of different hybrid optical amplifiers (EDFA-EDFA, and EDFA-SOA) a simulation model of a 10Gbit/s 4 channel dense wavelength division multiplexing transmission system with different encoding technique non-return-to zero(NRZ) encoding and return to zero (RZ) encoding technique at $0.8 \mathrm{~nm}$ equal channel spacing along with DCF for compensating dispersion has been introduced. The simulation set up block diagram is shown in Figure 1.

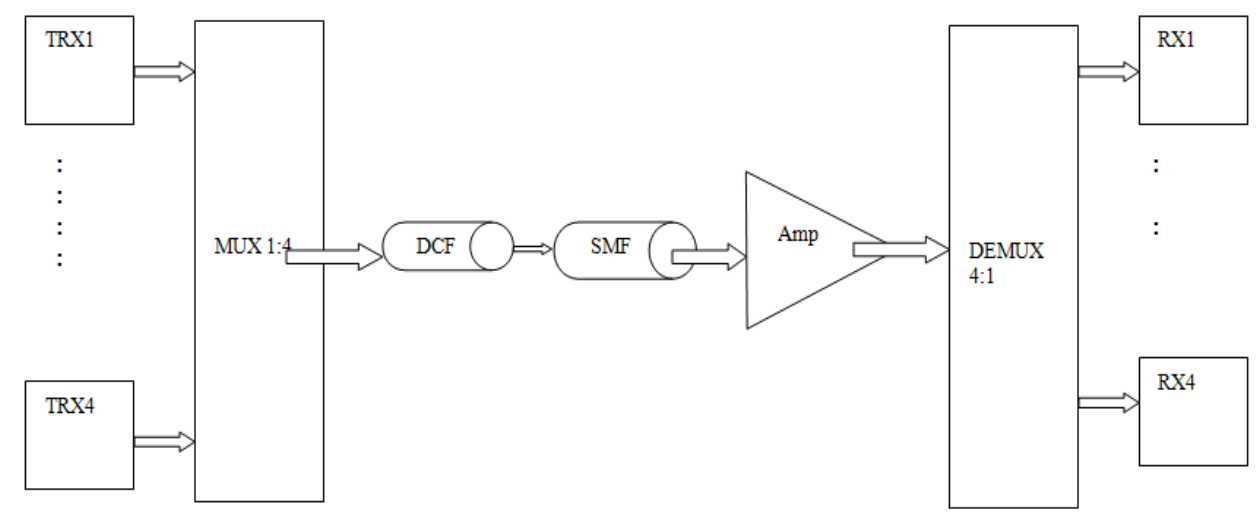

\section{Figure 1. Block Diagram for 40Gbps DWDM System using Hybrid Optical Amplifier}

The transmitter block consists of 4 channel transmitters, each of them operating at its own frequency in the range from $193.1 \mathrm{THz}$ to $193.4 \mathrm{THz}$ with $0.8 \mathrm{~nm}$ equal channel spacing. Each transmitter includes a Data Source(pseudo random sequence), NRZ coder or RZ coder, Modulator (match zehnder) and a Continuous wave Laser source. Then all of the 4 generated optical signals are transmitted over single mode optical fiber at different distances from 100 to $250 \mathrm{Km}$ having dispersion 16.75 $\mathrm{ps} / \mathrm{nm} / \mathrm{Km}$ along with DCF having dispersion $-80 \mathrm{ps} / \mathrm{nm} / \mathrm{Km}$ for compensating dispersion. Then from optical fibre signal are post amplified by hybrid optical amplifier(EDFA-EDFA and EDFA-SOA), dispersion is compensated by means of DCF. Then compare the performance of DWDM system using EDFA-EDFA hybrid amplifier with EDFA-SOA hybrid optical amplifier with different encoding techniques (NRZ and RZ). At the receiver section there is present 4 reciever blocks, each receiver block consist of PIN photodiode which converts the optical signal to an electrical signal, further followed by $4^{\text {th }}$ order low pass Bessel filter, 3R 
regenerator and eye diagram analyser. Bessel filter and 3R regenerator are used to reconstruct the original signal. From the eye diagram analyzer, the values of $Q$ factor, average eye opening and BER can be analyzed at different $\mathrm{km}$ of $40 \mathrm{Gbps}$ DWDM system.

\section{Results and Discussions}

\section{a. EDFA-EDFA Hybrid Optical Amplifier with NRZ Format}

The DWDM system using EDFA-EDFA hybrid optical amplifier with NRZ encoding technique provides good result upto $200 \mathrm{~km}$ by compensating dispersion with DCF of length $10.468 \mathrm{~km}$. The quality factor at $200 \mathrm{~km}$ link length is 9.523 and bit error rate is $10^{-22}$. The result using EDFA-EDFA at $200 \mathrm{~km}$ link length with NRZ modulation technique as shown in Figure 2.

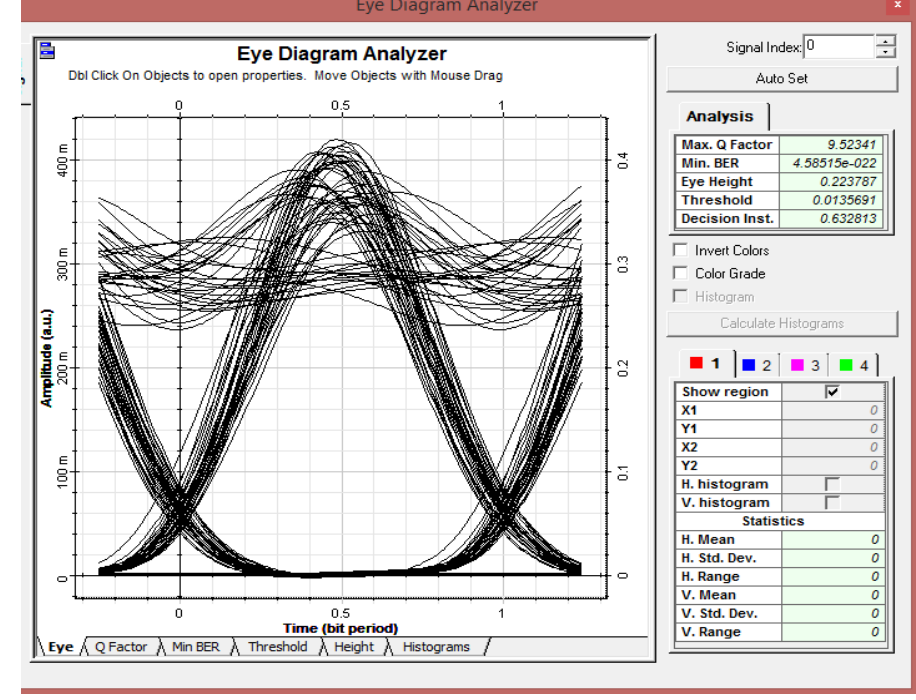

Figure 2. EDFA-EDFA Hybrid Optical Amplifier with NRZ Encoding Technique at a Distance of $200 \mathrm{~km}$

\section{b. EDFA-SOA Hybrid Optical Amplifier with NRZ Format}

The DWDM system using EDFA-SOA hybrid optical amplifier with NRZ encoding technique provides good result upto $100 \mathrm{~km}$ by compensating dispersion with DCF of length $10.468 \mathrm{~km}$. The quality factor at $100 \mathrm{~km}$ link length is 7.499 and bit error rate is $10^{-14}$. The result using EDFA-SOA at $100 \mathrm{~km}$ link length with NRZ modulation technique as shown in Figure 3. 


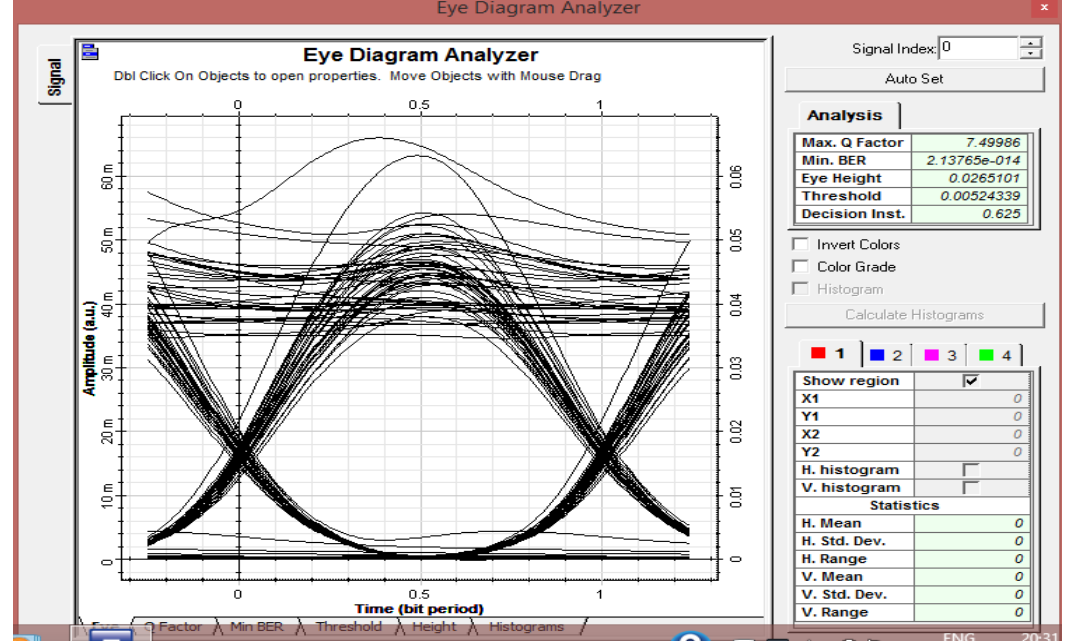

Figure 3 EDFA-SOA Hybrid Optical Amplifier with NRZ Encoding Technique at a Distance of $100 \mathrm{~km}$

\section{c. EDFA-EDFA Hybrid Optical Amplifier with RZ Format}

The DWDM system using EDFA-EDFA hybrid optical amplifier with RZ encoding technique provides good result upto $250 \mathrm{~km}$ by compensating dispersion with DCF of length $10.468 \mathrm{~km}$. The quality factor at $250 \mathrm{~km}$ link length is 38.25 and bit error rate is $10^{-320}$. The result using EDFA-EDFA at $250 \mathrm{~km}$ link length with RZ modulation technique as shown in Figure 4.

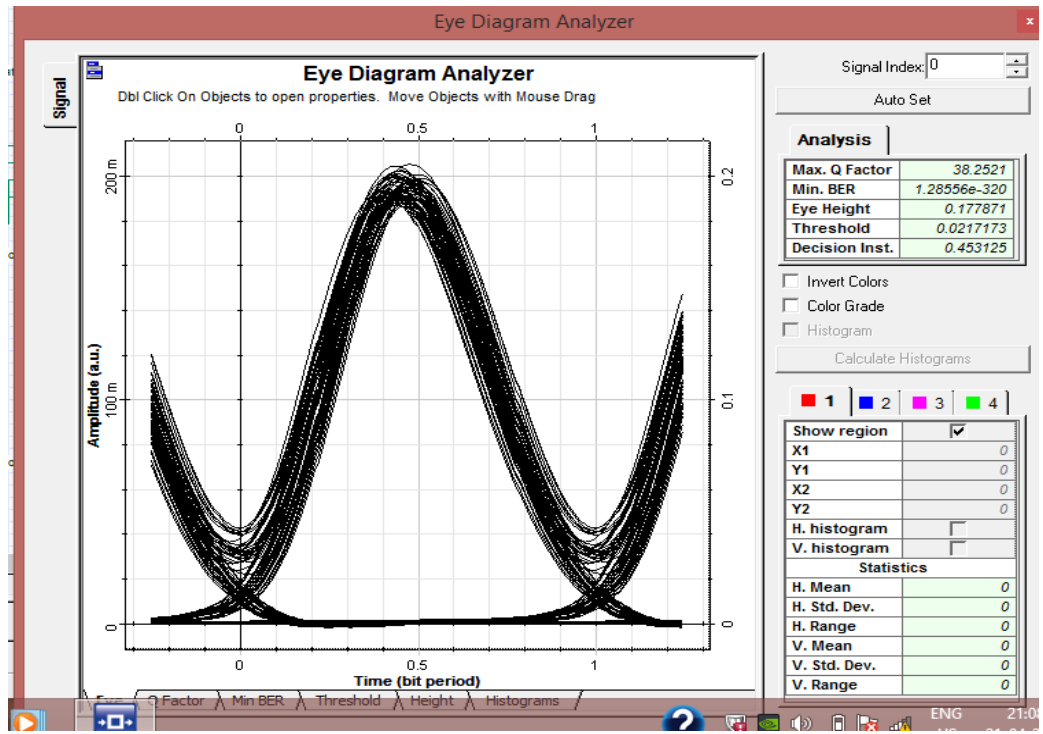

Figure 4. EDFA-EDFA Hybrid Optical Amplifier with RZ Encoding Technique at a Distance of $250 \mathrm{~km}$

\section{d. EDFA-SOA Hybrid Optical Amplifier with RZ Format}

The DWDM system using EDFA-SOA hybrid optical amplifier with RZ encoding technique provides good result upto $120 \mathrm{~km}$ by compensating dispersion with DCF of length $8.375 \mathrm{~km}$.. The quality factor at $120 \mathrm{~km}$ link length is 7.0386 and bit error rate is $10^{-13}$. The result using EDFA-SOA at $120 \mathrm{~km}$ link length with RZ modulation technique as shown in Figure 5. 


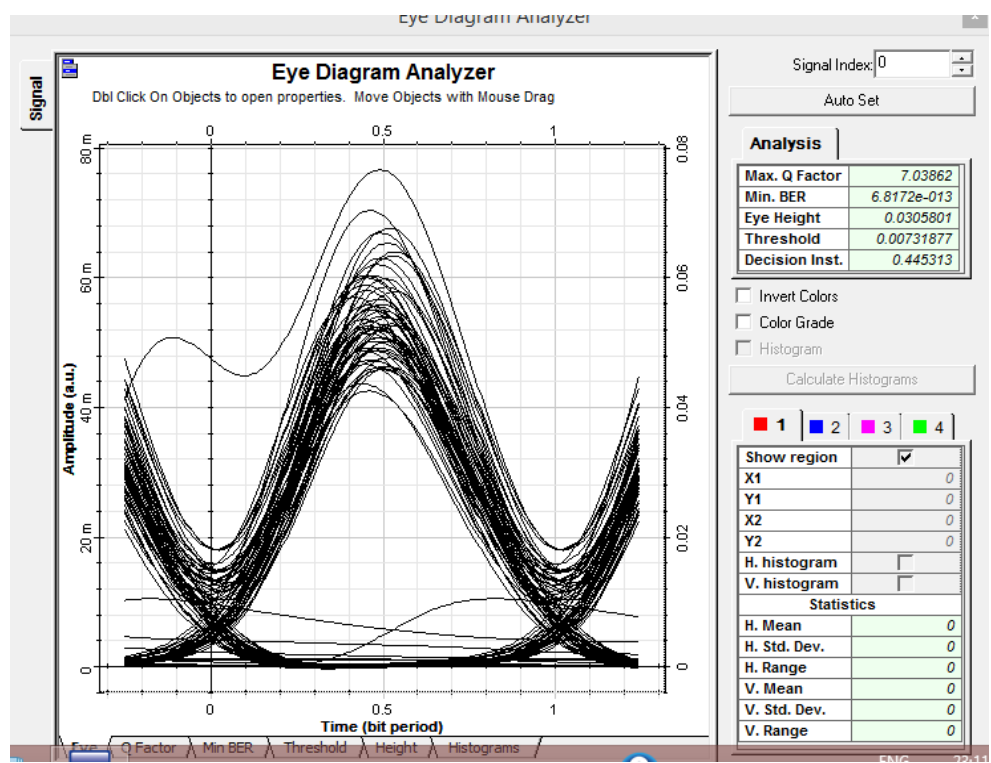

Figure 5. EDFA-SOA Hybrid Optical Amplifier with RZ Encoding Technique at a Distance of $120 \mathrm{~km}$

Table 1. For 40Gbps DWDM System with Hybrid Optical Amplifier using NRZ Formats

\begin{tabular}{|c|c|c|}
\hline Parameters & $\begin{array}{c}\text { EDFA-EDFA hybrid } \\
\text { amplifier }\end{array}$ & $\begin{array}{c}\text { EDFA-SOA hybrid } \\
\text { amplifier }\end{array}$ \\
\cline { 2 - 3 } & At $200 \mathrm{~km}$ & At $100 \mathrm{~km}$ \\
\hline Q-factor & 9.523 & 7.499 \\
\hline BER & $10^{-22}$ & $10^{-14}$ \\
\hline
\end{tabular}

Table 2. DWDM System with Hybrid Optical Amplifier using RZ Formats

\begin{tabular}{|c|c|c|}
\hline Parameters & $\begin{array}{c}\text { EDFA-EDFA hybrid } \\
\text { amplifier }\end{array}$ & $\begin{array}{c}\text { EDFA-SOA hybrid } \\
\text { amplifier }\end{array}$ \\
\cline { 2 - 3 } & At $250 \mathrm{~km}$ & At $120 \mathrm{~km}$ \\
\hline Q-factor & 38.521 & 7.0386 \\
\hline BER & $10^{-320}$ & $10^{-13}$ \\
\hline
\end{tabular}

\section{Conclusions}

Implementation of $40 \mathrm{Gbps}$ DWDM system has been investigated to evaluate BER and Q-factor at different optical length in $(\mathrm{Km})$ using various hybrid optical amplifier (EDFAEDFA and EDFA-SOA) with NRZ and RZ encoding technique along with DCF fibre for compensating dispersion. It is concluded that EDFA-EDFA yields better result than EDFA-SOA hybrid optical amplifiers on the basis of Q-factor. EDFA-EDFA provides good result upto $200 \mathrm{~km}$ as compared to EDFA-SOA upto $100 \mathrm{~km}$ with NRZ modulation format. For RZ format EDFA-EDFA also provides good result upto $250 \mathrm{~km}$ as compared to EDFA-SOA which provides upto $120 \mathrm{~km}$. It is concluded that Quality factor of system using RZ format is more than system using NRZ format and also communication using RZ format achieves more distance than NRZ format. 


\section{ACKNOWLEDGEMENTS}

The author wishes to thanks Ms. Jyotsana for the guidance provided in this research work.

\section{References}

[1] S. Olonkins, V. Bobrovs and G. Ivanovs, Electronics Electrical Eng., vol. 7, no. 133, (2012).

[2] G. Arora and S. Dewra, International Journal of Electronics and Communication Engineering Research, vol. 1, no. 6, (2013).

[3] H. Bhagwan, T. Gulati and B. Rawat, International Journal of Engineering Research and Applications (IJERA), vol. 2, no. 663, (2012).

[4] M. M. J. Martini, C. E. S. Castellani, M. J. Pontes, M. R. N. Ribeiro and H. J. Kalinowski, Proceedings of SBMO/IEEE MTT-S International Microwave and Optoelectronics Conference (IMOC), (2009) November 3-6, Belem, Brazil.

[5] S. Singh and R. S. Kaler, Optik, vol. 123, no. 1636, (2012).

[6] A. Sheetal, A. K. Sharma and R. S. Kaler, ELSEVIER Optic international journal for light and electron optics, vol. 121, no. 739, (2010).

[7] M. M. Lodro and M. A. Joyo, Proceedings of International Conference on Information and Computer Networks (ICICN), (2012) February 26-28, Singapore.

[8] G. Kaur, M. L. Singh and M. S. Patterh, Emerald Journal of Engineering, Design and Technology, vol. 8 , no. 28, (2010).

[9] V. Bobrovs, S. Olonkins, O. Ozolins, J. Porins and G. Lauks, OSA Publications, 3rd Fiber Optics in Access Network - FOAN, (2012) October 3-4, St Petersburg, Russian Federation.

[10] V. Bobrovs and G. Ivanovs, Latvian Journal of Physics and Technical Sciences, vol. 45, no. 3, (2008). 